\title{
В. В. Вежновец
}

Научно-практический иентр НАН Беларуси по биоресурсам, Минск, Республика Беларусь

\section{ВЛИЯНИЕ ПОВЫШЕНИЯ ТЕМПЕРАТУРЫ НА СОСТОЯНИЕ ПОПУЛЯЦИИ РЕЛИКТОВОГО РАЧКА LIMNOCALANUS MACRURUS SARS В MEЗОTРОФНОМ ОЗЕРЕ}

\author{
(Представлено членом-корреспондентом В. П. Семенченко)
}

\begin{abstract}
Впервые приведены данные о влиянии высокой летней температуры на состояние популяции редкого и охраняемого вида - реликтовой каланоидной копеподы Limnocalanus macrurus. Показано, что повышение поверхностной температуры ведет к падению концентрации кислорода в гиполимнионе в средне-глубоких озерах Беларуси и катастрофически снижает численность реликта, что может привести к его полному вымиранию.

Ключевые слова: температура, реликт, озеро, концентрация кислорода, плотность.
\end{abstract}

\section{V. Vezhnavets}

Scientific and Practical Center for Bioresources of the National Academy of Sciences of Belarus, Minsk, Republic of Belarus

\section{INFLUENCE OF A TEMPERATURE INCREASE ON THE CONDITION OF THE RELIC CRUSTACEAN LIMNOCALANUS MACRURUS SARS POPULATION IN A MESOTROPHIC LAKE}

\author{
(Communicated by Corresponding Member V. P. Semenchenko)
}

The data on the influence of a high summer temperature on the condition of the population of a rare and protected species a relic calanoid copepod Limnocalanus macrurus are presented for the first time. It is shown that an increase in surface temperature leads to a decrease in oxygen concentration in the hypolimnion in medium-deep lakes of Belarus and catastrophically reduces the density of the relict, which can lead to its complete extinction.

Keywords: temperature, relict, lake, oxygen concentration, density.

Введение. Лимнокалянус длиннохвостый (Limnocalanus macrurus) - один из реликтовых видов копепод, сохранившихся в озерах Беларуси со времен последнего оледенения [1;2]. Вид подвержен риску вымирания за счет высокой требовательности к качеству воды. Так из 10 озер, где он ранее отмечался, сейчас сохранился только в пяти, занесен в Красную Книгу Беларуси и соседних Прибалтийских стран. Стабильные популяции до сих пор сохранились только в четырех озерах (Ричи, Долгое, Южный Волос и Сита), расположенных в Витебской области [3].

Вид стенотермный, холодолюбивый, основная часть популяции располагается в глубоких слоях воды при низкой температуре и достаточно высоком содержании растворенного кислорода. В связи с естественными процессами эвтрофирования и загрязнения в населяемых им озерах наблюдается снижение качества воды, падение концентрации кислорода, что приводит к исчезновению его из ряда водоемов. К названным выше традиционным угрозам популяциям этого реликта добавляется аномально высокая температура, наблюдающаяся сейчас в отдельные годы, влияние которой приводит к перестройкам в пространственной структуре и функционировании экосистем [4; 5]. Влияние теплового загрязнения техногенного происхождения на популяцию лимнокалянуса ранее нами прослежено на водоеме-охладителе АЭС [6], естественное повышение температуры на популяцию этого вида не изучено.

Цель работы - установить влияние повышения температуры на многолетние количественные показатели популяции.

Материалы и методы исследования. Исследования были проведены с разной периодичностью с 1988 по 2015 г. в последней декаде июля на озере Сита (Браславский р-н, Витебская обл.). Сита - средне-глубокий водоем. Его площадь составляет 1,88 км²; максимальная глубина - 28,5 м;

(с) Вежновец В. В., 2017. 


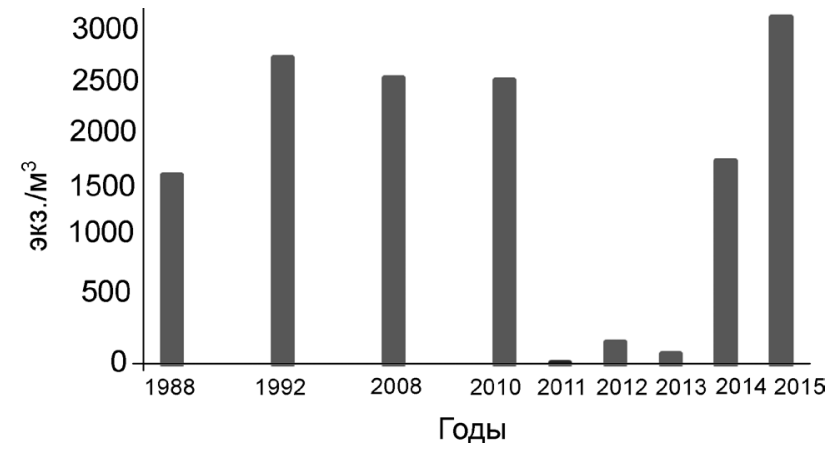

Рис. 1. Многолетние изменения плотности лимнокалянуса в оз. Сита

Fig. 1. Long-term changes of Limnocalanus density in the lake Sita средняя - 7,6 м при объеме воды - 14,37 млн м³. Озеро по генетическому типу относят к водоемам мезотрофного типа с чертами олиготрофии [7].

Пробы зоопланктона отобраны в пелагиали на станции с максимальной глубиной количественной планктонной сетью с диаметром ячеи фильтрующего конуса 100 мкм, от поверхности до дна через 5 м глубины. Лабораторная обработка проб проводилась в счетной камере Богорова под бинокулярным микроскопом МБС-10 при увеличении $4 \times 8$, учитывались все возрастные стадии рачка.

Результаты и их обсуждение. В процессе многолетних наблюдений в оз. Сита установлено катастрофическое снижение численности L. macrurus после аномально теплого лета 2010 года (рис. 1).

Численность лимнокалянуса в этом озере оставалась стабильной в течение продолжительного периода наблюдений (с 1988 г.) и ее значения составляли около 2 тыс. экз/м³. После «теплой европейской волны» 2010 г. плотность резко снизилась до предельных величин и составила в 2011 г. только единицы в кубометре. Восстановление популяции продолжалось три последующих года и только в последние два года численность достигла величин, наблюдавшихся ранее, а в 2015 г. даже превзошла прежние.

Ранее нами была показана реакция этого вида на дефицит кислорода зимой в оз. Волос, которая выражалась в замедлении развития и нарушении жизненного цикла и, соответственно, в изменении возрастного состава [3]. При этом в середине лета в составе популяции еще были младшие стадии развития, а к осени, к началу размножения, животные успевали стать половозрелыми. Падение плотности на следующий год после зимнего недостатка кислорода было постепенным и не критическим. Механизм снижения численности в этом водоеме объяснялся разбалансировкой между пиками развития лимнокалянуса и кормовых водорослей.

В отличие от оз. Волос, в оз. Сита в этот же период лета животные были представлены, как и ранее, взрослыми особями шестой копеподитной стадии с незначительным количеством пятого копеподита, т. е. возрастной состав при снижении численности не изменился. При этом падение плотности было резким - с 2,5 тыс. экз $/ \mathrm{M}^{3}$ до единиц в кубометре воды. Такое явление для этого вида отмечено впервые и требует дальнейшего изучения.

Для оз. Сита характерна температурная стратификация и разделение водной толщи на прогреваемый эпилимнион до 5-6 м, переходную зону металимнион и низкотемпературный гиполимнион, где температура в летнее время фактически не изменяется, оставаясь в узких пределах от 4,1 до $6,4{ }^{\circ} \mathrm{C}$. Лимнокалянус как стенотермно холодолюбивый вид населяет в этом водоеме гиполимнион, при вертикальных миграциях регистрируется в металимнионе, но не встречается в эпилимниальной зоне [3; 8]. По литературным данным, оптимальная температура обитания этого вида в озерах Беларуси $1-8{ }^{\circ} \mathrm{C}$, максимальная - может достигать $17-18$, но обычно во время суточных миграций животные не пересекают изотерму $13{ }^{\circ} \mathrm{C}$ [3].

Температурные условия для поверхностных и придонных слоев воды в этом водоеме за все годы наблюдений представлены в таблице. В зоне обитания рачка она остается в пределах оптимальной зоны. Поверхностная температура незакономерно изменялась от 19,9 до $26,2{ }^{\circ} \mathrm{C}$, но за все годы исследований только в 2010 г. была выше $25^{\circ} \mathrm{C}$.

Содержание кислорода в разные годы изменялось значительно в гиполимнионе и достигало критических значений для этого вида четырежды из 6 последних лет наблюдений, начиная с 2010 года. Корреляции между поверхностной температурой и содержанием кислорода в гиполимнионе не обнаружено (коэффициент корреляции -0,18), что связано, вероятно, с разными условиями формирования температурного расслоения водной толщи (ход весенней температуры, ветровое воздействие и т. п.) и последующим весенним развитием водорослей. 
Изменение температуры и содержания кислорода в оз. Сита по многолетним данным

Changes of temperature and oxygen concentration in lake Sita on long-term data

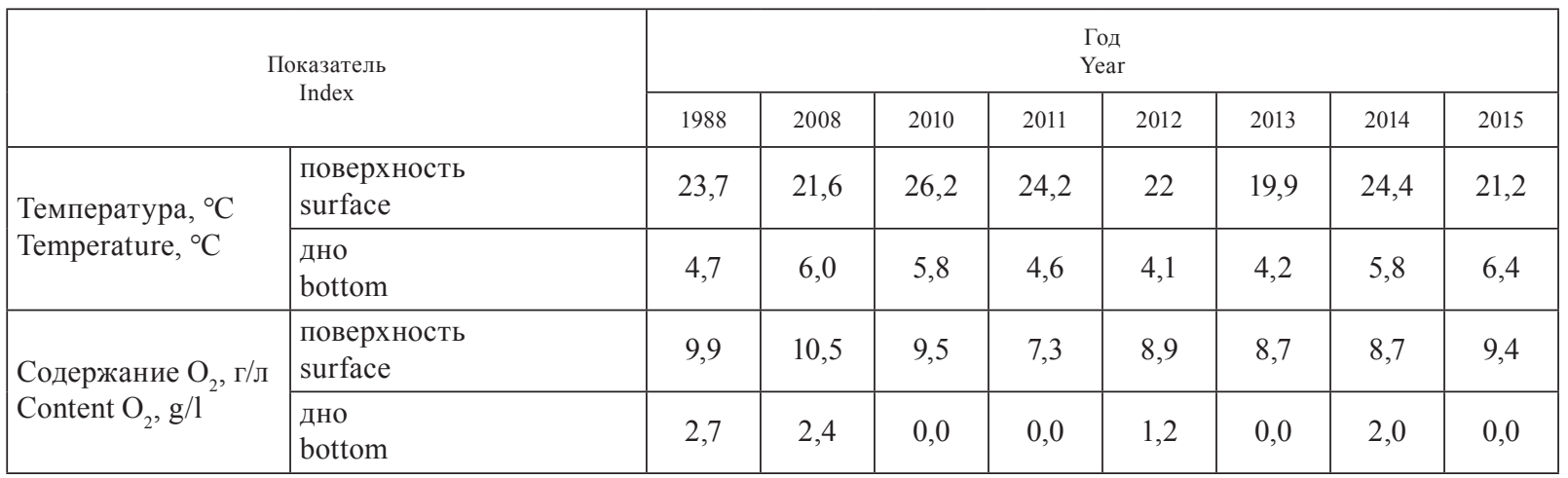

Влияние неблагоприятных условий обитания, наблюдавшихся в 2010 г., повлияло на численность популяции не сразу, минимальные значения плотности последовали на следующий год (лаг-эффект). Это связано с моноцикличностью вида и приуроченностью размножения к холодному времени года (декабрь-март), т. е. в создавшихся неблагоприятных условиях вероятно произошло резкое увеличение смертности и к периоду размножения половозрелые животные сохранились в незначительном количестве. Угнетенное состояние популяции сохранялось в течение трех последующих лет наблюдений. При этом за эти годы благоприятные кислородные условия были в 2014 г., когда популяция возродилась. В последний год наблюдений содержание кислорода опять снизилось до критических значений, что позволяет прогнозировать следующий спад численности в 2016 г.

Расположение животных в вертикальном столбе воды в годы с разным содержанием кислорода отличалось значительно (рис. 2). При достаточном для жизнедеятельности уровне насыщения кислородом гиполимниона, популяция держится в придонных слоях воды (1988 г.), а при недостатке кислорода лимнокалянус перемещается в более высокие горизонты (2010 г.), но не встречается в зоне эпилимниона с высокой температурой.

Рассчитанная глубина расположения «ядра» популяции (средневзвешенное значение в столбе воды) в течение периода наблюдений изменялась от 14 до 25 м (рис. 3). Предельной величиной для этого вида была принята концентрация кислорода менее 2 мг/л. Это значение считается нижней границей оптимума для данного вида, при которой начинается смертность животных уже при температуре $4{ }^{\circ} \mathrm{C}[1 ; 3]$. В годы с достаточным количеством кислорода основная часть популяции лимнокалянуса оставалась на обычных для него глубинах, ниже 20 м, а в годы с недостатком кислорода в дневное время перемещалась в более высокие слои воды, т. е. активно избегала зоны с низким содержанием кислорода. Вертикальное дневное расположение животных в столбе воды четко следовало за глубиной начала недостатка кислорода для этого вида, коэффициент корреляции при этом составил 0,93.

Проведены расчеты зоны выживания лимнокалянуса (пространственной ниши по Гриннеллу), в которой температура была ниже $13{ }^{\circ} \mathrm{C}$ и содержание кислорода более 2 мг/л в вертикальном столбе воды для этого вида в разные годы наблюдений (рис. 4). Область выживания

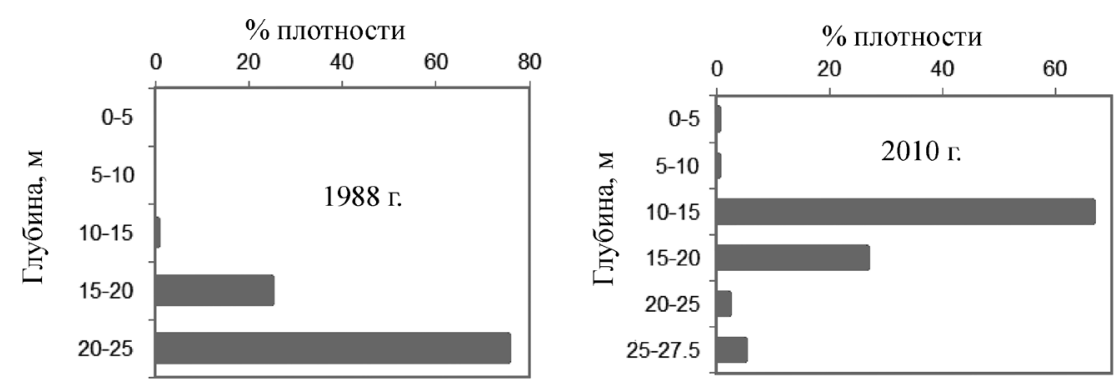

Рис. 2. Дневное вертикальное расположение лимнокалянуса при разном содержании кислорода в гиполимнионе Fig. 2. Daytime vertical location of Limnocalanus at different oxygen concentrations in the hypolimnion 

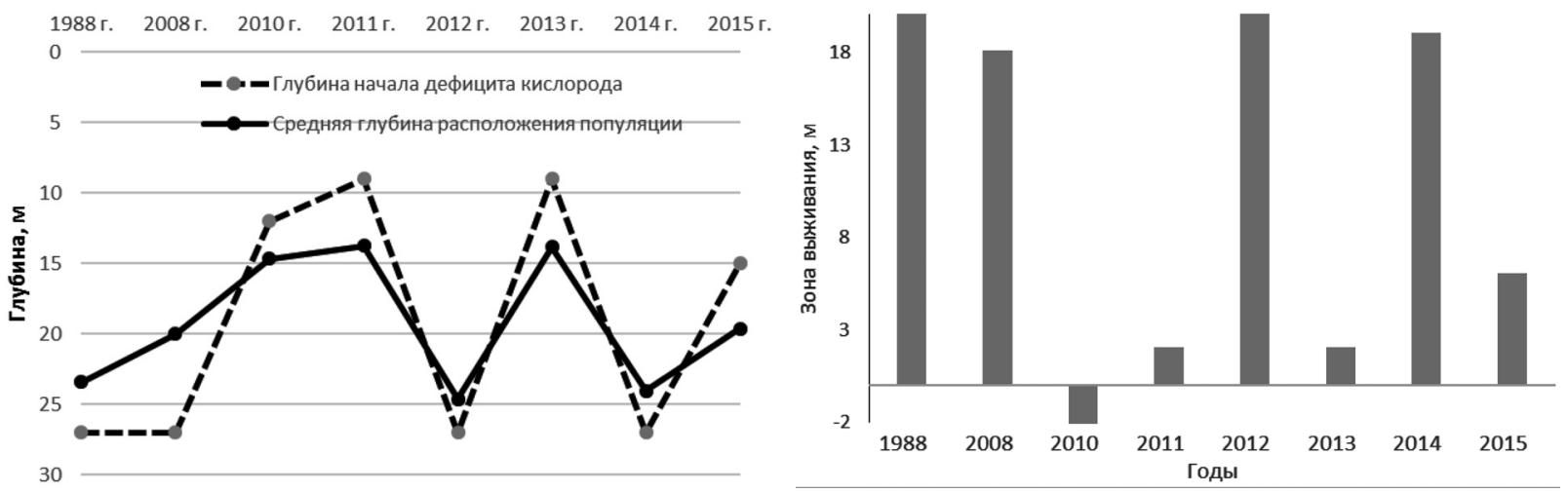

Рис. 3. Изменение дневного вертикального расположения Рис. 4. Изменение размера зоны нормальной жизнедеяядра популяции при разной концентрации кислорода тельности (выживания) лимнокалянуса в разные годы в гиполимнионе наблюдений

Fig. 3. Vertical daytime location change of «population nucle- Fig. 4. Changes of the size of normal life (survival) zone Limus» at different oxygen concentrations in the hypolimnion nocalanus in different years of observations

значительно изменялась по годам - от 20 до -2 м. Вертикальное пространство, занимаемое популяцией, расширялось в годы, богатые кислородом, и было крайне узким в годы с дефицитом. При этом отрицательные значения наблюдались только в 2010 г., что свидетельствует об отсутствии зоны благоприятных условий для жизнедеятельности популяции в этот год, что не регистрировалось в другие годы наблюдений. По данным последних лет, несмотря на невысокие значения температуры, наблюдался дефицит кислорода, но зона приемлемых условий (низкая температура и достаточное количество кислорода) остается еще достаточной для выживания популяции или переживания неблагоприятных условий до осеннего полного перемешивания водных масс, когда происходит обогащение воды кислородом и последующее размножение животных. Корреляционный анализ численности вида с шириной пространственной ниши (зоны выживания) со смещением в один год показал слабую зависимость $(0,56)$ этих показателей, вероятно, из-за малого числа наблюдений.

Процесс снижения содержания кислорода в столбе воды глубже эпилимниона рассмотрен нами ранее, при этом было предположено [4], что резкое повышение температуры в эуфотном слое вызывает бурное развитие водорослей, которые не успевают потребить консументы. Эти водоросли отмирают, опускаются в нижележащие слои воды, где идут процессы их разложения и интенсивное потребление кислорода.

Резкое падение численности лимнокалянуса происходит за счет отмирания особей в условиях отсутствия кислорода. Не исключается и выедание этого вида планктоядными рыбами во время подъема и концентрации рачка в более высоких слоях воды в дневное время, где доступность его как корма возрастает.

Заключение. Впервые получены данные о влиянии повышения температуры на состояние популяции реликтовой каланоидной копеподы Limnocalanus macrurus. Показано, что повышение поверхностной температуры ведет к падению концентрации кислорода в гиполимнионе в среднеглубоких озерах Беларуси и катастрофически снижает численность реликта, что может привести к его полному вымиранию.

Благодарности. Работа выполнена при частичной поддержке БРФФИ (договор № Б16МС-016).
Acknowledgement. The work is partially supported by the Belarusian Republican Foundation for Fundamental Research (Agreement no. Б16MC-016).

\section{Список использованных источников}

1. Сущеня, Л. М. Биология и продукция ледниковых реликтовых ракообразных / Л. М. Сущеня, В. П. Семенченко, В. В. Вежновец. - Минск: Наука и техника, 1986. - 160 с.

2. Вежновец, В. В. Ракообразные (Cladocera, Copepoda) в водных экосистемах Беларуси. Каталог. Определительные таблицы / В. В. Вежновец. - Минск: Бел. наука, 2005. - 150 с.

3. Вежновец, В. В. Биология реликтового рачка Limnocalanus grimaldii var. macrurus и его продукционноэнергетическая характеристика: автореф. дисс. ... канд. биол. наук / В. В. Вежновец. - Минск, 1984. - 24 с. 
4. Вежновец, В. В. Влияние повышения температуры на вертикальное распределение зоопланктона в мезотрофном стратифицированном озере / В. В. Вежновец, В. П. Семенченко // Докл. НАН Беларуси. - 2011. - Т. 55, № 5. C. $72-75$.

5. Vezhnavets, V. V. Zooplankton community / V. V. Vezhnavets, D. V. Malatkou, K. Arbačiauskas // Zoology and Ecology. - 2017. - Vol. 24, iss. 2. - P. 108-127. doi.org/10.1080/21658005.2014.925241.

6. Vezhnavets, V. The vertical distribution of zooplankton in the mesotrophic stratified lakes Rica and Sita in relation to temperature / V. Vezhnavets, A. Skute, D. Molotkov // 6th International conference "Research and Conservation of biological Diversity in Baltic Region”, Daugavpils, 28-29 April, 2011. - Daugavpils, 2011. - P. 139.

7. Якушко, О. Ф. Белорусское Поозерье. История развития и современное состояние озер Северной Белоруссии / О. Ф. Якушко. - Минск: Вышэйш. шк., 1971. - 336 с.

8. Вежновец, В. В. Пространственное распределение Limnocalanus grimaldii var. macrurus Sars. в оз. Ю. Волос / В. В. Вежновец // Итоги и перспективы гидробиологических исследований в Белоруссии. - Минск, 1983. - С. 83-88.

\section{References}

1. Sushchenya L. M., Semenchenko V. P., Vezhnovets V. V. Biology and products of glacial relic crustaceans. Minsk, Nauka i tekhnika Publ., 1986. 160 p. (in Russian)

2. Vezhnovets V. V. Crustacean (Cladocera, Copepoda) in the aquatic ecosystems of Belarus. Catalog. Identification tables. Minsk, Belaruskaya navuka Publ., 2005. 150 p. (in Russian)

3. Vezhnovets V. V. Biology of the relic small crustacean Limnocalanus grimaldii var. macrurus and its productionenergy characteristic. Minsk, 1984. 24 p. (in Russian)

4. Vezhnovets V. V., Semenchenko V. P. Impact of warming on a vertical distribution of zooplankton in a mesotrophic stratifield lake. Doklady Natsional'noi akademii nauk Belarusi [Doklady of the National Academy of Sciences of Belarus], 2011, vol. 55, no. 5, pp. 72-75. (in Russian)

5. Vezhnavets V. V., Malatkou D. V., Arbačiauskas K. Zooplankton community. Zoology and Ecology, 2014, vol. 24, no. 2, pp. 108-127. doi.org/10.1080/21658005.2014.925241.

6. Vezhnavets V., Skute A., Molotkov D. The vertical distribution of zooplankton in the mesotrophic stratified lakes Rica and Sita in relation to temperature. 6th International conference "Research and Conservation of biological Diversity in Baltic Region”, Daugavpils, 28-29 April, 2011. Daugavpils, 2011, p. 139.

7. Yakushko O. F. Belarusian Lake District. The history of development and the modern state of the lakes of the Northern Belarus. Minsk, Vysheishaja shkola Publ., 1971. 336 p. (in Russian)

8. Vezhnovets V. V. Space distribution of Limnocalanus grimaldii var. macrurus Sars. in Like South Volos. Outcomes and perspectives of hydrobiological investigations in Belarus. Minsk, 1983, pp. 83-88. (in Russian)

\section{Сведения об авторе}

Вежновеи Василий Васильевич - канд. биол. наук, доцент, вед. науч. сотрудник, НПЦ НАН Беларуси по биоресурсам (ул. Академическая, 27, 220072, Минск, Республика Беларусь). E-mail: vvv@biobel.bas-net.by.

\section{Для цитирования}

Вежновец, В. В. Влияние повышения температуры на состояние популяции реликтового рачка Limnocalanus macrurus Sars в мезотрофном озере / В. В. Вежновец // Докл. Нац. акад. наук Беларуси. - 2017. - Т. 61, № 1. С. $73-77$.

\section{Information about the author}

Vezhnavets Vasili Vasilievich - Ph. D. (Biology), Assistant Professor, Leading researcher, Scientific and Practical Center for Bioresources of the National Academy of Sciences of Belarus (27, Akademicheskaya Str., 220072, Minsk, Republic of Belarus). E-mail: vvv@biobel.bas-net.by.

\section{For citation}

Vezhnavets V. V. Influence of a temperature increase on the condition of the relic crustacean Limnocalanus macrurus Sars population in a mesotrophic lake. Doklady Natsional'noi akademii nauk Belarusi [Doklady of the National Academy of Sciences of Belarus], 2017, vol. 61, no. 1, pp. 73-77. (in Russian) 